\title{
Using recombinant Rho protein antagonist in acute spinal cord injury; does this go further from conventional decompressions?
}

\author{
Nima Hafezi-Nejad ${ }^{1,2}$ and Vafa Rahimi-Movaghar ${ }^{1,2 *}$ \\ ${ }^{1}$ Department of Neurosurgery, Sina Trauma and Surgery Research Center, Tehran University of Medical Sciences, Tehran, Iran \\ 2 Student's Scientific Research Center, Tehran University of Medical Sciences, Tehran, Iran \\ *Correspondence: v_rahimi@tums.ac.ir
}

Edited by:

Elliot J. Roth, Rehabilitation Institute of Chicago, USA

Reviewed by:

Elliot J. Roth, Rehabilitation Institute of Chicago, USA

New evidence has suggested the Rho signaling pathway as a target for treatment in acute spinal cord injury (SCI). The Rho signaling pathway plays an important role in neuronal growth inhibition after a CNS injury. Block of Rho pathway is a new potential method to improve recovery after an SCI. Other studies by our group had further revealed the underlying mechanisms of this pathway (Firouzi et al., 2011).

BA-210 (Trademarked as Cethrin) is a newly designed Rho pathway antagonist. A "Phase I/IIa Clinical Trial of a Recombinant Rho Protein antagonist in Acute Spinal Cord Injury" by Fehlings et al. (2011) has been recently published to evaluate BA-210 specifically in course of SCI. Implications of the findings of this study can potentially change the management of this condition around the world. However, we would like to highlight some concerns.

The article referenced two guideline reviews on SCI and its spontaneous recovery (Fawcett et al., 2007; Steeves et al., 2007). They reported the results of recovery after the application of BA-210 as well. This may cause misinterpretation when comparing their results with the mentioned guidelines. Guidelines were reviews of investigations including those by Kirshblum et al. (2004), Waters et al. (1993), Geisler et al. (2001) and European Multicenter study in Spinal Cord Injury (EMSCI). The first observations to note are the differences between the study groups. Excluding gunshots, stab wounds, and transecting injuries in the current study, leaves the only those patients who are more likely to recover. The same occurs in excluding patients who are more likely to die in the following 6 months as well as conditions that make patients unable or unwilling to participate. Their criteria for excluding selected patients raise the concern that the study group was more likely to recover spontaneously. Neither of the above mentioned conditions was assigned in the compared studies.

The current study reported 31\% (5/16) recovery from ASIA A to at least ASIA $\mathrm{C}$ at cervical level of injury along with $6.3 \%(2 / 32)$ recovery at thoracic level. They encountered an overall of recovery of around $14.6 \%$ (7/48). The authors considered this to be encouraging. However, we compared this to a meta-analysis by La Rosa et al. They analyzed the summation of at least 10 series of reports on patients with complete SCI. Early decompression was matched to the timing of surgery in current study. In all, $42 \%$ (50/119) of the patients were considered neurologically improved. Improvement was defined by at least one grade progress according to the Frankel's scale; including both cervical and thoracic levels of injury. Although $42 \%$ recovery in La Rosa et al.'s metaanalysis regards to advances from ASIA A to $\mathrm{B}$, it is still far behind $14.6 \%$. This can be a proper baseline and reference for comparison; beside the $10 \%$ predicted rate of conversion derived for untreated cervical SCI in the Fehlings et al.'s article (La Rosa et al., 2004). Other studies insist on the low rate of recovery after thoracic SCI. However, T12 injuries are similar in nature to L1 injuries rather than thoracic level injuries. Separations of injuries on T12 are still recommended to avoid over-reporting in recoveries of thoracic SCI (RahimiMovaghar, 2005; Rahimi-Movaghar et al., 2006).
Fehlings et al. (2011) did not adjust the results for dural tears. Dural tears were reported in $31 \%$ of the patients. This can be of importance in assessing Cethrin's tolerability and side effects. Moreover, it can potentially affect the neurological outcome after drug administration. Presence of dural tears leaves the possibility of confounding effects intact.

Finally, can we expect a single application of an agent in a proximate time to the injury to declare further trend of "linear recovery" in its following 12 months? Further investigations as well as phase II and III clinical trials can answer this question. Revealing the actual efficacy of BA-210, particularly by a more inclusive study group and an adjusted comparison is needed.

\section{REFERENCES}

Fawcett, J. W., Curt, A., Steeves, J. D., Coleman, W. P., Tuszynski, M. H., Lammertse, D., et al. (2007). Guidelines for the conduct of clinical trials for spinal cord injury as developed by the ICCP panel: spontaneous recovery after spinal cord injury and statistical power needed for therapeutic clinical trials. Spinal Cord 45, 190-205.

Fehlings, M. G., Theodore, N., Harrop, J., Maurais, G., Kuntz, C., Shaffrey, C. I., et al. (2011). A phase I/IIa clinical trial of a recombinant Rho protein antagonist in acute spinal cord injury. J. Neurotrauma 28, 787-796.

Firouzi, M., Sabouni, F., Deezagi, A., Pirbasti, Z. H., Poorrajab, F., and Rahimi-Movaghar, V. (2011). Schwann cell apoptosis and p75(NTR) siRNA. Iran. J. Allergy Asthma Immunol. 10, 53-59.

Geisler, F. H., Coleman, W. P., Grieco, G., and Poonian, D. (2001). Measurements and recovery patterns in a multicenter study of acute spinal cord injury. Spine (Phila Pa 1976) 26, S68-S86.

Kirshblum, S., Millis, S., Mckinley, W., and Tulsky, D. (2004). Late neurologic recovery after traumatic spinal cord injury. Arch. Phys. Med. Rehabil. 85, 1811-1817. 
La Rosa, G., Conti, A., Cardali, S., Cacciola, F., and Tomasello, F. (2004). Does early decompression improve neurological outcome of spinal cord injured patients? Appraisal of the literature using a meta-analytical approach. Spinal Cord 42, 503-512.

Rahimi-Movaghar, V. (2005). Efficacy of surgical decompression in the setting of complete thoracic spinal cord injury. J. Spinal Cord Med. 28, 415-420.

Rahimi-Movaghar, V., Vaccaro, A. R., and Mohammadi, M. (2006). Efficacy of surgical decompression in regard to motor recovery in the setting of conus medullaris injury. J. Spinal Cord Med. 29, 32-38.
Steeves, J. D., Lammertse, D., Curt, A., Fawcett, J. W., Tuszynski, M. H., Ditunno, J. F., et al. (2007). Guidelines for the conduct of clinical trials for spinal cord injury (SCI) as developed by the ICCP panel: clinical trial outcome measures. Spinal Cord 45, 206-221.

Waters, R. L., Adkins, R. H., Yakura, J. S., and Sie, I. (1993). Motor and sensory recovery following complete tetraplegia. Arch. Phys. Med. Rehabil. 74, 242 .

Received: 01 November 2012; accepted: 19 January 2013; published online: 05 February 2013.
Citation: Hafezi-Nejad $N$ and Rahimi-Movaghar V (2013) Using recombinant Rho protein antagonist in acute spinal cord injury; does this go further from conventional decompressions? Front. Neur. 4:5. doi: 10.3389/fneur.2013.00005

This article was submitted to Frontiers in Spinal Cord Medicine, a specialty of Frontiers in Neurology.

Copyright (C) 2013 Hafezi-Nejad and RahimiMovaghar. This is an open-access article distributed under the terms of the Creative Commons Attribution License, which permits use, distribution and reproduction in other forums, provided the original authors and source are credited and subject to any copyright notices concerning any third-party graphics etc. 